\title{
Power training and postmenopausal hormone therapy affect transcriptional control of specific co-regulated gene clusters in skeletal muscle
}

\author{
Eija Pöllänen • Vidal Fey • Timo Törmäkangas • Paula H. A. Ronkainen • \\ Dennis R. Taaffe • Timo Takala • Satu Koskinen • Sulin Cheng • Jukka Puolakka • \\ Urho M. Kujala • Harri Suominen • Sarianna Sipilä • Vuokko Kovanen
}

Received: 27 October 2009 / Accepted: 15 March 2010/Published online: 13 April 2010

(C) The Author(s) 2010. This article is published with open access at Springerlink.com

\begin{abstract}
At the moment, there is no clear molecular explanation for the steeper decline in muscle performance after menopause or the mechanisms of counteractive treatments. The goal of this genome-wide study was to identify the genes and gene clusters through which power training (PT) comprising jumping activities or estrogen containing hormone replacement therapy (HRT) may affect skeletal muscle properties after menopause. We used musculus vastus lateralis samples from early stage postmenopausal
\end{abstract}

Electronic supplementary material The online version of this article (doi:10.1007/s11357-010-9140-1) contains

supplementary material, which is available to authorized users.

E. Pöllänen · T. Törmäkangas · P. H. A. Ronkainen ·

S. Sipilä

Gerontology Research Centre, University Jyväskylä,

Jyväskylä, Finland

E. Pöllänen $(\varangle) \cdot$ P. H. A. Ronkainen $\cdot S$. Cheng $\cdot$

U. M. Kujala $\cdot$ H. Suominen $\cdot$ V. Kovanen

Department of Health Sciences,

University Jyväskylä,

Jyväskylä, Finland

e-mail: eija.pollanen@jyu.fi

V. Fey

VTT,

Turku, Finland

D. R. Taaffe

School of Human Movement Studies,

University of Queensland,

Brisbane, Australia
(50-57 years old) women participating in a yearlong randomized double-blind placebo-controlled trial with PT and HRT interventions. Using microarray platform with over 24,000 probes, we identified 665 differentially expressed genes. The hierarchical clustering method was used to assort the genes. Additionally, enrichment analysis of gene ontology (GO) terms and Kyoto Encyclopedia of Genes and Genomes (KEGG) pathways was carried out to clarify whether assorted gene clusters are enriched with particular functional categories. The

T. Takala

Oulu Deaconess Institute, University of Oulu,

Oulu, Finland

T. Takala

Department of Health Sciences, University of Oulu,

Oulu, Finland

S. Koskinen

Department of Physical Performance,

Norwegian School of Sport Science,

Oslo, Norway

J. Puolakka

Central Finland Central Hospital, Jyväskylä, Finland

U. M. Kujala

ORTON Orthopedic Hospital, Invalid Foundation,

Helsinki, Finland 
analysis revealed transcriptional regulation of $49 \mathrm{GO} /$ KEGG categories. PT upregulated transcription in "response to contraction"-category revealing novel candidate genes for contraction-related regulation of muscle function while HRT upregulated gene expression related to functionality of mitochondria. Moreover, several functional categories tightly related to muscle energy metabolism, development, and function were affected regardless of the treatment. Our results emphasize that during the early stages of the postmenopause, muscle properties are under transcriptional modulation, which both PT and HRT partially counteract leading to preservation of muscle power and potentially reducing the risk for aging-related muscle weakness. More specifically, PT and HRT may function through improving energy metabolism, response to contraction as well as by preserving functionality of the mitochondria.

Keywords Transcriptome-wide study · Power training · Plyometric training - Estrogen deprivation . Hormone replacement therapy $\cdot$ Menopause .

Skeletal muscle characteristics

\section{Introduction}

Menopause, the transition from the reproductive to non-reproductive stage, is a complex physiological process, often accompanied by additional effects of aging (Nelson 2008). In addition to reproductive viability, deterioration in musculoskeletal properties begins to accumulate (Kallman et al. 1990; Phillips et al. 1993; Samson et al. 2000), which may lead to severe consequences for the quality of life and the ability to recover from physical traumas ultimately reducing the healthspan of women. Therefore, early preventative actions to maintain adequate muscle performance in later life are needed.

So far the best prevention strategy against agingrelated weakness is physical exercise (Greenlund and Nair 2003; Taaffe 2006). Strength, endurance, and power training have been found to exhibit beneficial albeit differential effects on aging musculature (e.g., Hoppeler et al. 1985; Häkkinen et al. 2000; Roth et al. 2001; Timmons et al. 2005; Porter 2006; Hazell et al. 2007; Henwood et al. 2008; Orsatti et al. 2008). Progressive power training such as undertaken in the current study, is associated with enhanced quality of life, i.e., physical functioning and well-being (Katula et al. 2008), neuromuscular functions involving rapid force production (Sipilä et al. 2001; Taaffe et al. 2005), and bone formation (Cheng et al. 2002). Moreover, muscle power is essential for many daily tasks such as climbing stairs, rising from chair, and preventing a fall after a slip leading a number of recent studies (Hazell et al. 2007; Paterson et al. 2007; Katula et al. 2008; Orr et al. 2008) to conclude that strategies improving muscle power and composition are essential in order to prevent old age disability. Therefore, power training is promising training mode for postmenopausal women whose risk for osteoporosis and neuromuscular dysfunction might otherwise be increased. However, the genome-wide effects of this specific type of training on skeletal muscle have not, until now, been investigated.

In addition to physical exercise, the restoration of female sex hormones to near pre-menopausal levels may represent one way to attenuate functional decline and muscle loss after menopause. Indeed, several randomized controlled trials (RCT) have shown that hormone replacement therapy (HRT) increases muscle mass and improves neuromuscular performance when used in the beginning of the postmenopausal period (Skelton et al. 1999; Sipilä et al. 2001; Dobs et al. 2002; Taaffe et al. 2005). In addition, a co-twin study, in which monozygotic HRT users were compared to their non-using sisters, showed that long-term HRT treatment is associated with greater muscle power, higher walking speed, and decreased total body and thigh fat content (Ronkainen et al. 2009). However, not all trials with HRT have reported beneficial effects on muscle and physical function (Ribom et al. 2002; Tanko et al. 2002; Kenny et al. 2005) indicating the need for additional research to clarify this discrepancy.

In our yearlong RCT, the exercise and hormone replacement therapy-study (Ex/HRT), the effects of plyometric power training and HRT on bone as well as muscle structure and function in postmenopausal women were studied (Sipilä et al. 2001; Cheng et al. 2002; Taaffe et al. 2005). We found a significant $6 \%$ increase in muscle power with power training and 7\% with HRT, while a $5 \%$ reduction was observed in control participants without any treatments (Sipilä et al. 2001). Running speed increased by $4 \%$ both after HRT and power training and reduced by $2 \%$ in the controls (Taaffe et al. 2005). Moreover, knee extensor muscle density increased significantly by both power 
training and HRT (Taaffe et al. 2005) reflecting beneficial changes in muscle composition in favor of muscle tissue itself on the expense of adipose tissue (Goodpaster et al. 2000). Knee extensor muscle crosssectional area increased by $6 \%$ with HRT (Sipilä et al. 2001). Our earlier microarray study investigating the effects of 1-year HRT use showed that the postmenopausal women without treatment have notable changes in their muscle transcriptome and that these changes were largely counteracted by the use of HRT (Pöllänen et al. 2007). To the best of our knowledge, other microarray studies on the effects of HRT or power training on skeletal muscle of postmenopausal women have not previously been undertaken.

The purpose of this ancillary genome-wide analysis of the Ex/HRT study was to identify gene clusters that are affected by progressive power training, use of HRT or recent menopause, and thus may induce the adaptive changes in skeletal muscle characteristics. To accomplish our goal, we combined previously obtained microarray data with completely new data from eight power trainers and four control women (totally ten HRT users, eight trainers, and nine nontreated women). This allowed us to identify both unique and overlapping effects of the two treatments on muscle transcriptome.

\section{Materials and methods}

\section{Study design and interventions}

The detailed description of the study design has been reported by Sipilä et al. 2001. The trial is registered in the Current Controlled Trials with ISCTN number ISRCTN49902272 (http://www.controlled-trials.com/ ISRCTN49902272). Briefly, we enrolled 1,333 women at age 50-57 years living in the area of the municipality of Jyväskylä in Finland. From these women, 118 went through an extensive medical and physical examination including determination of their menopausal status as well as eligibility to the study. To be eligible for the trial, participants had to have no serious medical conditions; no current or previous use of medication including estrogen, fluoride, calcitonin, biophosphonates, or steroids; last menstruation at least 0.5 years but not more than 5 years ago; FSH level above $30 \mathrm{IU} / \mathrm{L}$; and no contraindications for exercise and HRT. Finally, we randomly assigned 80 women fulfilling the inclusion criteria, i.e., being at the very early stage following menopause, to one of four study groups: power training (PT, $n=20)$, HRT $(n=20)$, PT+HRT $(n=20)$, and control $(\mathrm{CO}, n=20)$.

For the current microarray analysis, baseline and 12-month muscle samples were available from eight PT, ten HRT, and nine CO women. Seventeen participants were lost during the intervention, and muscle samples from both baseline and postintervention (12-months) were not available from 14 subjects. Moreover, one participant did not consent for the microarray study. The analysis does not include the PT + HRT group due to the small number of tissue samples available $(n=6)$. The participants available for the microarray study did not differ significantly from the whole study sample in any of the tested muscle phenotype variables at baseline or in changes during the intervention.

Muscle biopsies obtained from the mid-part of musculus vastus lateralis (midpoint between the greater trochanter and the lateral joint line of the knee) were taken at baseline and after completion of the study as previously described (Pöllänen et al. 2007). The biopsy protocol was standardized within the study in order to avoid sampling-induced variation. All muscle biopsies were taken from the side of the dominant hand approximately at the same time of day by the same experienced physician. The 12-month biopsy was taken $1 \mathrm{~cm}$ above the previous biopsy cicatrix within 3 to 5 days after completion of the intervention. The histological evaluation of the samples did not reveal any signs of damage, such as central nuclei, in any of the samples.

The detailed description of the interventions is reported in Sipilä et al. 2001. In brief, PT participants underwent a progressive plyometric training program for the lower limbs, which comprised two supervised sessions per week and four home-based unsupervised sessions per week. The training was performed in a circuit format including bounding, drop jumping, hopping, and skipping performed at high velocity in order to improve muscle power production and to produce high-impact loading for bones. The training program progressed in the number of rotations performed, volume of work undertaken as well as height of obstacles for bounding and height for drop jumping. Each supervised session included three to four resistance training exercises for the upper body and commenced with a warm-up period and conclud- 
ed with a cool-down period of stretching activities. HRT and CO subjects were advised to maintain their daily routines without altering their physical activity patterns. The HRT treatment was conducted doubleblind. All study participants used either continuous, combined HRT preparation containing estradiol (2 mg) and or noretisterone acetate $(1 \mathrm{mg})$ preparation (Kliogest, Novo Nordisk, Copenhagen, Denmark) or placebo (composed of lactose monohydrate, cornstarch, gelatin, talc, and magnesium stearate, which were auxiliary substances in the Kliogest tablet) one tablet every day.

The study was carried out in accordance with the Declaration of Helsinki (48th WMA General assembly; 1996 1989) of the World Medical Association (www. wma.net) and was approved by the ethics committee of the Central Finland Health Care District. Informed consent was given by all subjects.

RNA preparation, cRNA generation, and array hybridization

The RNA preparation, cRNA generation, and array hybridization procedures have been previously described (Pöllänen et al. 2007). Briefly, Trizolreagent (Invitrogen, Carlsbad, CA, USA) was used to isolate RNA from biopsy samples homogenized on FastPrep FP120 apparatus (MP Biomedicals, Illkrich, France). The Experion (Bio-Rad Laboratories, Hercules, CA, USA) was used to inspect RNA concentration and quality. Only pure, good-quality RNA was used in further analysis (260/280 ratio >1.8). An Illumina RNA amplification kit (Ambion, Austin, TX, USA) was used according to the manufacturer's instructions to obtain biotin-labeled cRNA from $500 \mathrm{ng}$ of total RNA. Experion was used to perform quality control after amplification. Hybridization to the HumanRef-8 v1.0 or HumanWG-6 v1.0 BeadChips (Illumina Inc., San Diego, CA) as well as washing and scanning was performed according to the Illumina BeadStation 500x manual (revision C). Both samples (baseline and follow-up) from each study subject were always hybridized onto the same chip. The slides were scanned by confocal laser scanning system (Illumina BeadReader Rev. C, Illumina Inc., San Diego, CA, USA). The data were acquired by the BeadStudio Direct Hybridization V.1.5.0.34. The Turku Centre for Biotechnology (Turku, Finland) carried out the cRNA generation, array hybridizations, and quality control of the raw data. The data discussed in this publication have been deposited in NCBI's Gene Expression Omnibus (GEO; Edgar et al. 2002) and are accessible through GEO Series accession number GSE16907 (http://www.ncbi.nlm.nih. gov/geo/query/acc.cgi?acc=GSE16907). The MIAME guidelines were followed during array data generation, preprocessing, and analysis.

Array data preprocessing and validation

Raw gene expression data from eight PT and four $\mathrm{CO}$ participants were obtained by using Human WG-6 BeadChips (Illumina), while HumanRef-8 BeadChips (Illumina) were utilized for ten HRT and five CO participants. Raw data from both BeadChips were combined, and only the probes, which are identical in both platforms, were included in further analysis. Consequently, over 24,000 probes for approximately 21,000 NCBI RefSeq-transcripts were included. Signal for each transcript comes from approximately 30 independent technical replicates (beads) as described previously (Pöllänen et al. 2007). Quality control and visualization of the raw, combined expression data were performed with aid of box plots, hierarchical clustering, correlation matrix, and principal component analysis. Microarray data from the three study groups, i.e., PT, HRT, and CO, were normalized separately using the quantile normalization method implemented in the Affy-package (Gautier et al. 2004) of the R/ Bioconductor analysis software (www.r-project.org, www.bioconductor.org). Samples $(n=6)$ from three CO subjects were hybridized onto both Illumina platforms in order to compare the performance of previous and current arrays with the Pearson correlation coefficient test. Even though the correlation of the data produced by the same samples on different Illumina platforms was high $(r=0.88-0.94)$, the clear batch effect caused by two different platforms was visible. This was corrected in statistical analyses by using array type as a covariate.

\section{Data analysis}

After preprocessing the microarray data, the Limma package (Smyth 2004) of $\mathrm{R}$ was used to identify differentially expressed genes within each condition. The fold changes (FC) and $p$ values calculated by Limma methods were used as filtering criteria in order to detect genes up- or downregulated within each 
study group. The repeated measurements design and the batch effect caused by the usage of two different array types were taken into account in statistical testing. At this point, we chose to use quite low stringency thresholds ( $p$ value $<0.05$ and $|\mathrm{FC}|>1.2$ ) in order to list a reasonable number of the genes most likely to be differentially expressed. Decreasing or increasing the thresholds resulted in poorer cluster structures in the clustering of the filtered genes. Genes determined to be differentially expressed within at least one of the study groups were used in further analyses, which allow identifying co-regulated gene clusters, i.e., genes, which show consistent behavior being either up- or downregulated within each study group. We applied hierarchical clustering with Pearson's metrics to form clusters of most similarly behaving genes. The Pearson's correlation thresholds were set to 0.95. Additionally, extensive analysis of functional categories, i.e., gene ontology (GO) terms (Ashburner et al. 2000) and Kyoto Encyclopedia of Genes and Genomes (KEGG) pathways (Kanehisa et al. 2006), was carried out to clarify whether certain gene clusters are enriched with particular functional categories. Hypergeometric test and false positive discovery rate calculation were applied to identify the most significant categories. GenoSyst Ltd carried out the hierarchical clustering with enrichment analysis. The results obtained were further analyzed and processed in our lab. PatternViewer 2.39 (GenoSyst Ltd, Turku, Finland) was used to visualize the results.

\section{Results}

Co-regulated gene clusters

Differentially expressed genes were defined as genes that differed between follow-up and baseline samples within a study group with statistical threshold $p$ value $<0.05$ and $|\mathrm{FC}|>1.2$. These thresholds led to the discovery of 665 genes. In the PT group, 328 genes were upregulated and 182 downregulated, whereas in the HRT group, 34 genes were upregulated and 20 downregulated. The corresponding numbers for the $\mathrm{CO}$ group were 91 and 70, respectively. A non-redundant list of differentially expressed genes was used in the analysis of co-regulated gene clusters. Genes were sorted into eight significant and consistent clusters (Fig. 1, Table 1), which showed either study group- specific regulation or regulation into the same direction within all study groups. As seen in Fig. 1, genes within each cluster had a highly consistent expression pattern forming congruent cluster structure. The complete list of genes belonging to each cluster is presented in Table $\mathrm{S} 1$ as supporting information. For clarity, the official or commonly used acronym for gene names are used in the text and complete gene names with proper annotation are provided as supporting information in Table S2.

\section{Enrichment analysis}

The identified gene clusters (CL \#1-8) were diligently investigated in order to clarify whether they were enriched with particular GO terms or KEGG pathways. The algorithms used in the analysis allow determination of the percentage of false positive discovery (FP-\%), which enables monitoring the expected proportion of false positives among the discovered patterns. The FP-\% is obtained by comparing the permutated (at least 1,000 simulations) cluster-annotation pairs to the actually observed cluster-annotation pairs, and it allows efficient and visual selection of the significant cut-offs with an acceptable level of false discovery (Fig. 2). Due to the hypothesis-generating rather than hypothesis-proofing nature of the microarray studies, we selected FP-\% $<15 \%$. For the GO terms, a $p$ value $<0.0005$ was used as the cut-off value. With this cut-off, there are 26 significantly enriched GO terms from which theoretically three might be false positives (FP-\% 12\%). For the KEGG pathways, a $p$ value $<0.005$ is sufficient to tolerate similar proportion of false positives (FP-\% 10\%). This cut-off value identifies 23 significant KEGG pathways. The results of the enrichment analyses are presented in Tables 2 and 3 and thoroughly examined below with a summary of the main results presented in Fig. 3.

Power training-specific functional categories

The PT-specific gene clusters were CL \#2 and CL \#8, which consisted of 82 upregulated and 20 downregulated genes, respectively (Fig. 1b, h, Table 1). CL $\# 2$, which was specifically upregulated in the PT group and downregulated in the HRT and $\mathrm{CO}$ groups (Fig. 1b), including 13 genes without GO or KEGG annotations, 29 genes with annotation "cytoplasm," 


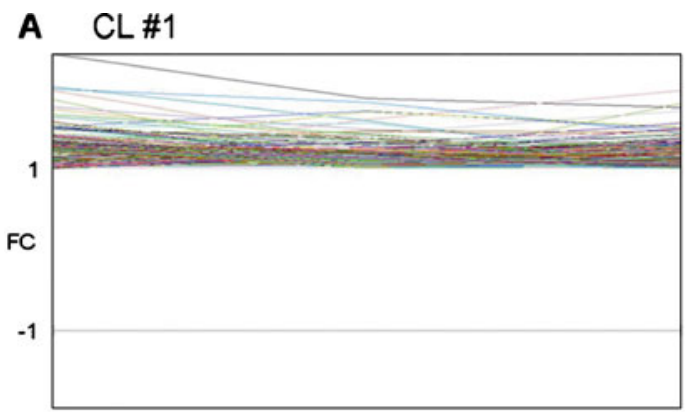

C $\mathrm{CL} \# 3$

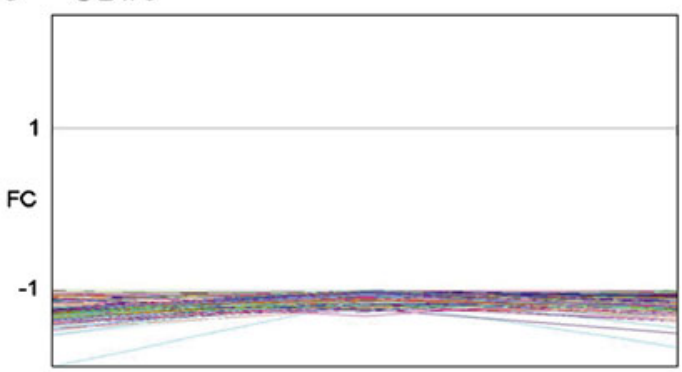

E $C L \# 5$

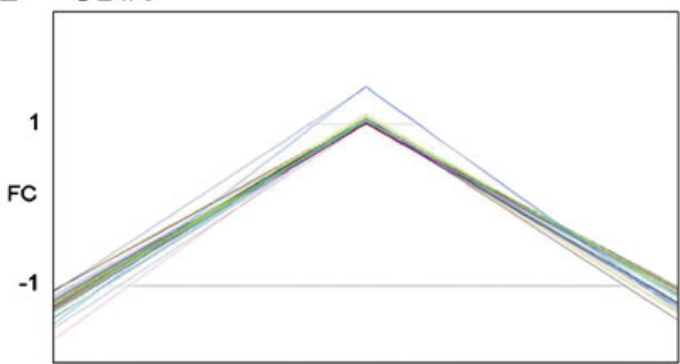

G $\quad \mathrm{CL} \# 7$

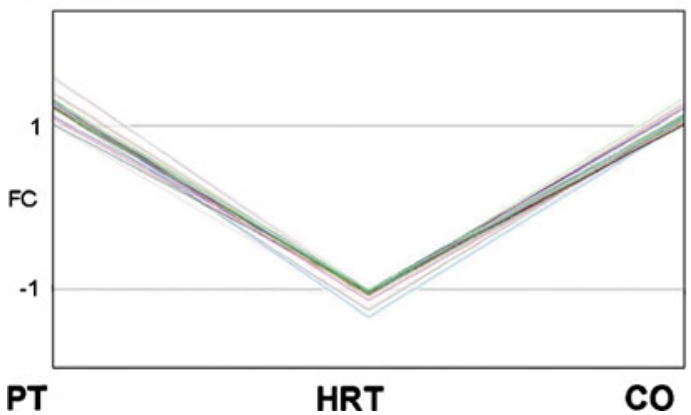

B $\mathrm{CL} \# 2$

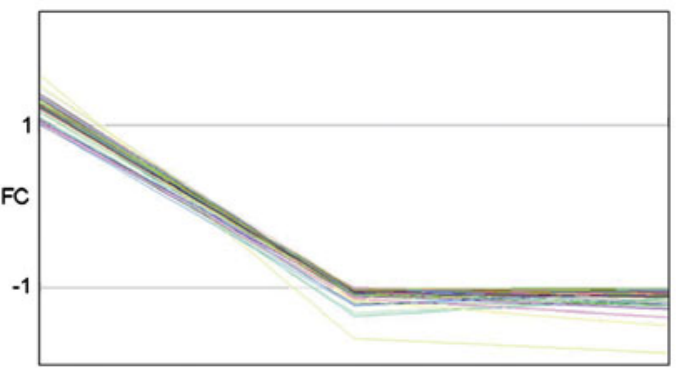

\section{D $\mathrm{CL} \# 4$}

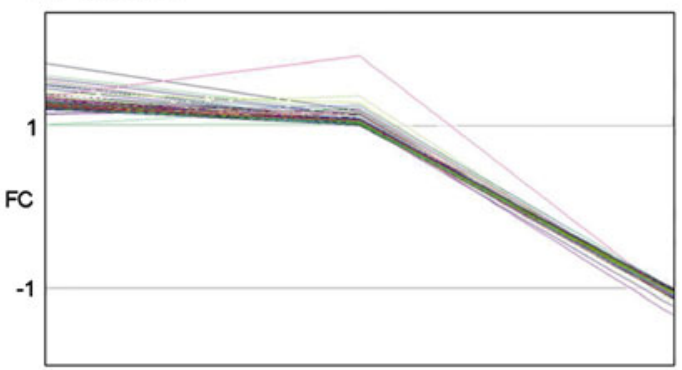

\section{F CL\#6}

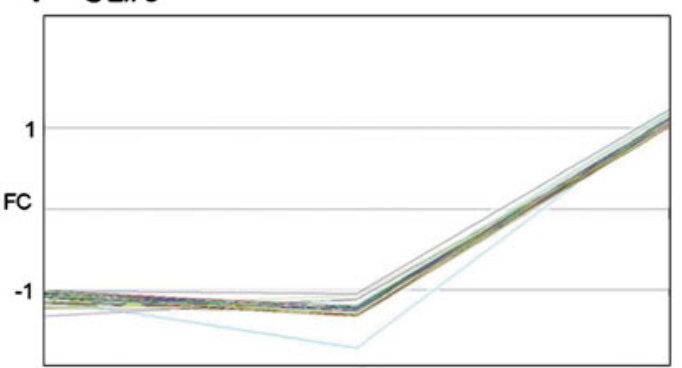

H CL \#8

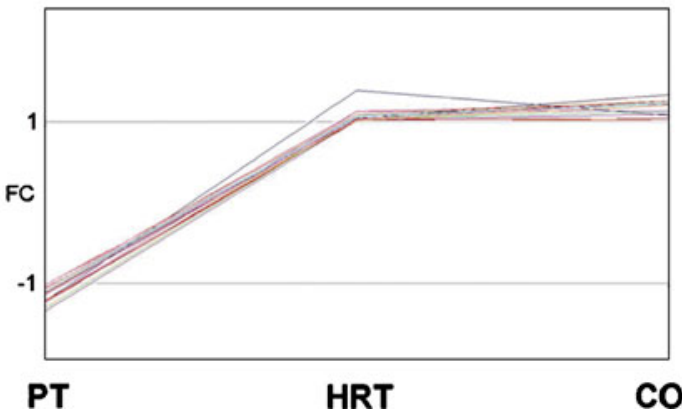

Fig. 1 Graphical view of the cluster structure within each cluster (CL \#1-CL \#8). Each line represents the mean fold change (FC) of a single gene

and 9 genes with annotation "actin binding" (Table 2). GO term "cytoplasm" constitutes $42 \%$ of the whole cluster and refers to all cellular actions taking place within the cytoplasmic entity of cells excluding the cell membrane and the nucleus. One of the most highly upregulated genes in CL \#2 was the STARS gene, which belongs to both "cytoplasm" and "actin binding" GO terms. STARS expression was 50\% upregulated among the PT women, whereas the expression was $16 \%$ downregulated within the HRT 
Table 1 Differentially expressed genes formed eight distinctive clusters

\begin{tabular}{llcccc}
\hline Clusters & Classification of the clusters & $\begin{array}{l}\text { Number of genes } \\
\text { in cluster }\end{array}$ & $\begin{array}{l}\text { Number of genes with } \\
\text { GO annotation }\end{array}$ & $\begin{array}{l}\text { Number of genes with } \\
\text { KEGG annotation }\end{array}$ & $\begin{array}{l}\text { Number of } \\
\text { unclassified genes }\end{array}$ \\
\hline CL \#1 & Uniform upregulation & 224 & 199 & 61 & 23 \\
CL \#2 & PT-specific upregulation & 82 & 69 & 20 & 13 \\
CL \#3 & Uniform downregulation & 139 & 119 & 46 & 22 \\
CL \#4 & Upregulation in the PT and & 81 & 71 & 21 & 3 \\
CL \#5 & HRT groups & 45 & 41 & 3 & 24 \\
CL \#6 & Downregulation in the PT & 43 & 19 & 12 & 7 \\
CL \#7 & HRT-specific downregulation & 31 & 24 & 5 \\
CL \#8 & PT-specific downregulation & 20 & 12 & 8 \\
\hline
\end{tabular}

and $46 \%$ downregulated within the CO group (Supporting Table S1). In addition, five genes encoding kinases, five encoding proteins related to apoptosis or proteolysis, four encoding signal transducers, four encoding proteins involved in regulation of transcription, and three encoding structural proteins were included in "cytoplasm" and/or "actin binding" GO terms. Moreover, CL \#2 was significantly enriched with "insulin" and "adipocytokine signaling" KEGG pathways (Table 3). The genes contributing most to the significance of these upregulated pathways in the PT group were MKNK2, GLUT4, FASN, AKT2, PRKAR2A, and STK11. The enrichment analysis did not reveal any statistically significant functional categories from CL \#8. This is probably due to the fact that $40 \%$ of the genes in this cluster were unclassified having neither GO nor KEGG annotation.

HRT-specific functional categories

The HRT-specific gene clusters were CL \#5, which consisted of 45 upregulated genes, and CL \#7, which included 31 downregulated genes (Fig. 1e, g, Table 1). Eleven genes did not have GO or KEGG annotation. According to enrichment analysis (Table 2), the use of HRT significantly upregulated transcription related to GO term "mitochondrion" and downregulated transcription of genes involved in "regulation of cell growth". We did not find any significant HRT-specific

Fig. 2 Distribution of false positive rate (FP-\%) at different $p$ values. The horizontal black line represents the selected threshold FP-\%. The $p$ values $<0.0005$ and $<0.005$ are sufficient to provide FP-\% $<15 \%$ confidence level for enrichment analysis of GO and KEGG, respectively, functional categories

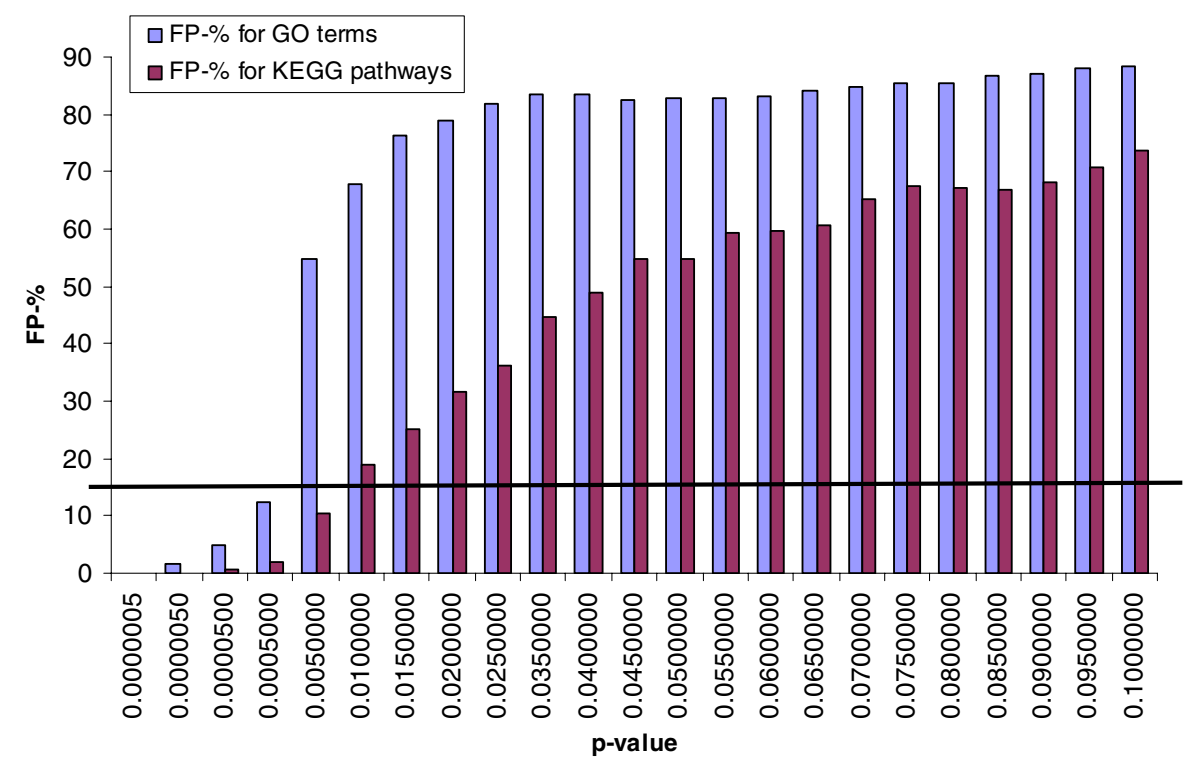


Table 2 Enrichment of GO terms into the co-regulated gene clusters. Note, numbers of genes are presented as they occur in the GO terms, meaning that they may be included in several different terms. Corrected $p$ value is obtained by multiplying by the number of hypothesis tested

\begin{tabular}{llll}
\hline GO ID & Term description & $\begin{array}{l}\text { Number of genes } \\
\text { in cluster/array }\end{array}$ & $\begin{array}{l}p \text { value } \\
\text { Corrected } \\
p \text { value }\end{array}$ \\
\hline
\end{tabular}

CL \#1: uniform upregulation, $199 \mathrm{GO}$-annotated genes

$\begin{array}{ll}\text { GO:0006936 } & \text { Muscle contraction } \\ \text { GO:0006941 } & \text { Striated muscle contraction } \\ \text { GO:0005977 } & \text { Glycogen metabolic process } \\ \text { GO:0007517 } & \text { Muscle development } \\ \text { GO:0007519 } & \text { Skeletal muscle development } \\ \text { GO:0004368 } & \text { Glycerol-3-phosphate dehydrogenase activity } \\ \text { GO:0030731 } & \text { Guanidinoacetate N-methyltransferase activity } \\ \text { GO:0016600 } & \text { Flotillin complex }\end{array}$

CL \#2: PT specific upregulation, 69 GO-annotated genes

$\begin{array}{ll}\text { GO:0003779 } & \text { Actin binding } \\ \text { GO:0005737 } & \text { Cytoplasm }\end{array}$

CL \#3: uniform downregulation, 119 GO-annotated genes

\begin{tabular}{|c|c|c|c|c|}
\hline GO:0047115 & Trans-1,2-dihydrobenzene-1,2-diol dehydrogenase activity & $3 / 4$ & $1.02 \mathrm{E}-6$ & 0.001 \\
\hline GO:0004033 & Aldo-keto reductase activity & $3 / 10$ & $2.98 \mathrm{E}-5$ & 0.013 \\
\hline GO:0047026 & 3-Alpha-hydroxysteroid dehydrogenase A-specific activity & $2 / 2$ & $4.07 \mathrm{E}-5$ & 0.018 \\
\hline GO:0047042 & 3-Alpha-hydroxysteroid dehydrogenase B-specific activity & $2 / 2$ & $4.07 \mathrm{E}-5$ & 0.018 \\
\hline GO:0006937 & Regulation of muscle contraction & $3 / 12$ & $5.41 \mathrm{E}-5$ & 0.024 \\
\hline GO:0005739 & Mitochondrion & $17 / 944$ & $1.07 \mathrm{E}-4$ & 0.048 \\
\hline GO:0045737 & Positive regulation of cyclin-dependent protein kinase activity & $2 / 3$ & $1.22 \mathrm{E}-4$ & 0.054 \\
\hline GO:0048306 & Calcium-dependent protein binding & $3 / 17$ & $1.63 \mathrm{E}-4$ & 0.073 \\
\hline O:0032052 & Bile acid binding & $2 / 4$ & $2.42 \mathrm{E}-4$ & 0.108 \\
\hline GO:0015721 & Bile acid and bile salt transport & $2 / 4$ & $2.42 \mathrm{E}-4$ & 0.108 \\
\hline GO:0001527 & Microfibril & $2 / 4$ & $2.42 \mathrm{E}-4$ & 0.108 \\
\hline GO:0016491 & Oxidoreductase activity & $11 / 481$ & $2.67 \mathrm{E}-4$ & 0.119 \\
\hline GO:0005578 & Proteinaceous extracellular matrix & $8 / 265$ & $3.09 \mathrm{E}-4$ & 0.138 \\
\hline GO:0031072 & Heat shock protein binding & $4 / 57$ & $4.87 \mathrm{E}-4$ & 0.217 \\
\hline \multicolumn{5}{|c|}{ CL \#5: HRT-specific upregulation, $41 \mathrm{GO}$-annotated genes } \\
\hline GO:0005739 & Mitochondrion & $12 / 944$ & $5.56 \mathrm{E}-7$ & 0.001 \\
\hline \multicolumn{5}{|c|}{ CL \#7: HRT-specific downregulation, 24 GO-annotated genes } \\
\hline GO:0001558 & Regulation of cell growth & $3 / 114$ & $4.15 \mathrm{E}-4$ & 0.052 \\
\hline
\end{tabular}

enrichment of KEGG-annotated pathways. Genes from "mitochondrion" included four genes encoding mitochondrial ribosomal proteins (MRPS12, MRPS36, $M R P L 27$, and MRPL33), one encoding mitochondrial chaperon (HSPE1), four genes directly involved with energy metabolism through oxidative phosphorylation (ATP5H and COX7A2), citric acid cycle (IDH3A) or fatty acid oxidation $(P E C I)$, and three genes involved with other mitochondrial functions (MTP18, PTPMT1, and TST). CL \#7 had one significant category, the "regulation of cell growth", which included three genes (INGIL, CHAD, and UBE2E3).

Functional categories affected by both PT and HRT

Both interventions, that is, one year of either PT or HRT, resulted in parallel upregulation of 81 genes (CL \#4) and downregulation of 43 genes (CL \#6) in contrast to that observed in the $\mathrm{CO}$ group (Fig. 1d, f, Table 1). Nine KEGG pathways were significantly 
Table 3 Enrichment of KEGG pathways into the coregulated gene clusters. Note, the number of genes is presented as they occur in the KEGG pathways, meaning that they may be included in several different pathways. Corrected $p$ value is obtained by multiplying by the number of hypothesis tested

\begin{tabular}{lll}
\hline KEGG ID Term name & $\begin{array}{l}\text { Number of genes in } \\
\text { cluster/array }\end{array}$ & $p$ value Corrected $p$ value \\
\hline
\end{tabular}

CL \#1: uniform upregulation, $61 \mathrm{KEGG-annotated} \mathrm{genes}$

\begin{tabular}{|c|c|c|c|c|}
\hline 04910 & Insulin signaling pathway & $9 / 163$ & $1.06 \mathrm{E}-4$ & 0.010 \\
\hline 00010 & Glycolysis/gluconeogenesis & $6 / 78$ & $2.81 \mathrm{E}-4$ & 0.026 \\
\hline 00030 & Pentose phosphate pathway & $4 / 29$ & $3.36 \mathrm{E}-4$ & 0.031 \\
\hline 05120 & Epithelial cell signaling in Helicobacter pylori infection & $5 / 79$ & $2.25 \mathrm{E}-3$ & 0.205 \\
\hline 04370 & VEGF signaling pathway & $5 / 91$ & $4.17 \mathrm{E}-3$ & 0.379 \\
\hline \multicolumn{5}{|c|}{ CL \#2: PT specific upregulation, $20 \mathrm{KEGG-annotated} \mathrm{genes}$} \\
\hline 04910 & Insulin signaling pathway & $5 / 163$ & $3.11 \mathrm{E}-4$ & 0.015 \\
\hline 04920 & Adipocytokine signaling pathway & $3 / 83$ & $3.75 \mathrm{E}-3$ & 0.184 \\
\hline \multicolumn{5}{|c|}{ CL \#3: uniform downregulation, 46 KEGG-annotated genes } \\
\hline 00980 & Metabolism of xenobiotics by cytochrome P450 & $7 / 65$ & $1.31 \mathrm{E}-6$ & $9.83 \mathrm{E}-5$ \\
\hline 00190 & Oxidative phosphorylation & $6 / 114$ & $4.62 \mathrm{E}-4$ & 0.035 \\
\hline 05216 & Thyroid cancer & $3 / 37$ & $4.16 \mathrm{E}-3$ & 0.312 \\
\hline 05010 & Alzheimer's disease & $3 / 38$ & $4.49 \mathrm{E}-3$ & 0.337 \\
\hline 03320 & PPAR signaling pathway & $4 / 77$ & $4.64 \mathrm{E}-3$ & 0.348 \\
\hline 00072 & Synthesis and degradation of ketone bodies & $2 / 12$ & $4.84 \mathrm{E}-3$ & 0.363 \\
\hline \multicolumn{5}{|c|}{ CL \#4: upregulation in the PT and HRT, 22 KEGG-annotated genes } \\
\hline 00710 & Carbon fixation & $3 / 29$ & $2.28 \mathrm{E}-4$ & 0.008 \\
\hline 04720 & Long-term potentiation & $4 / 85$ & $3.99 \mathrm{E}-4$ & 0.015 \\
\hline 05214 & Glioma & $4 / 88$ & $4.56 \mathrm{E}-4$ & 0.017 \\
\hline 05040 & Huntington's disease & $3 / 48$ & $1.03 \mathrm{E}-3$ & 0.038 \\
\hline 04020 & Calcium signaling pathway & $5 / 212$ & $1.65 \mathrm{E}-3$ & 0.061 \\
\hline 04912 & GnRH signaling pathway & $4 / 132$ & $2.09 \mathrm{E}-3$ & 0.077 \\
\hline 00010 & Glycolysis/gluconeogenesis & $3 / 78$ & $4.15 \mathrm{E}-3$ & 0.154 \\
\hline 04916 & Melanogenesis & $6 / 127$ & $1.06 \mathrm{E}-5$ & $3.93 \mathrm{E}-4$ \\
\hline 04910 & Insulin signaling pathway & $6 / 163$ & $4.43 \mathrm{E}-5$ & 0.002 \\
\hline \multicolumn{5}{|c|}{ CL \#6: downregulation in the PT and HRT, 3 KEGG annotated genes } \\
\hline 04360 & Axon guidance & $2 / 174$ & $3.31 \mathrm{E}-3$ & 0.007 \\
\hline
\end{tabular}

enriched among the upregulated genes (Table 3). These pathways included signaling related to carbohydrate metabolism (KEGG pathways 00710, 00010, and 04190 in Table 3) and calcium signaling (KEGG pathways 04020, 04720, 04912, 04916, 05040, and 05214 in Table 3). One of the most dramatically affected genes was $A L D O A$ with expression over $70 \%$ upregulated in the PT, 20\% upregulated in the HRT, and $10 \%$ downregulated in the $\mathrm{CO}$ group (Supporting Table S1). This enzyme catalyzes conversion of $\mathrm{C}_{6^{-}}$ carbohydrates to $\mathrm{C}_{3}$-carbohydrates being the initial step in the energy producing instead of energy consuming phase of glycolysis. Other upregulated genes contributing to carbohydrate metabolism through "glycolysis/glyconeogenesis" or "insulin signaling" were $P K M 2$, which catalyzes the last step of glycolysis, TPI1, PHKG1, FOXO1A, MKNK2, $C A L M 1$, and CALM3. According to KEGG annotations CALM1, CALM3, and PHKG1 are also involved in the "calcium signaling pathway". In addition, DCTN1, CaMK2A, CaMK2B, FZD7, and DVL1 genes, which encode proteins also involved in "calcium signaling", were upregulated in the PT and HRT women. 
Fig. 3 Main functional categories found to be affected in postmenopausal women. The number of genes is presented in nonredundant manner, i.e., "cytoplasm" includes a total of 29 genes from which nine are also included in the "response to contraction" and four in "energy metabolism" and therefore excluded from the "other cytoplasm-related" genes. The same approach was used in presenting the number of genes in all functional categories to avoid overpresenting the numbers. $\uparrow$ upregulation, $\downarrow$ downregulation

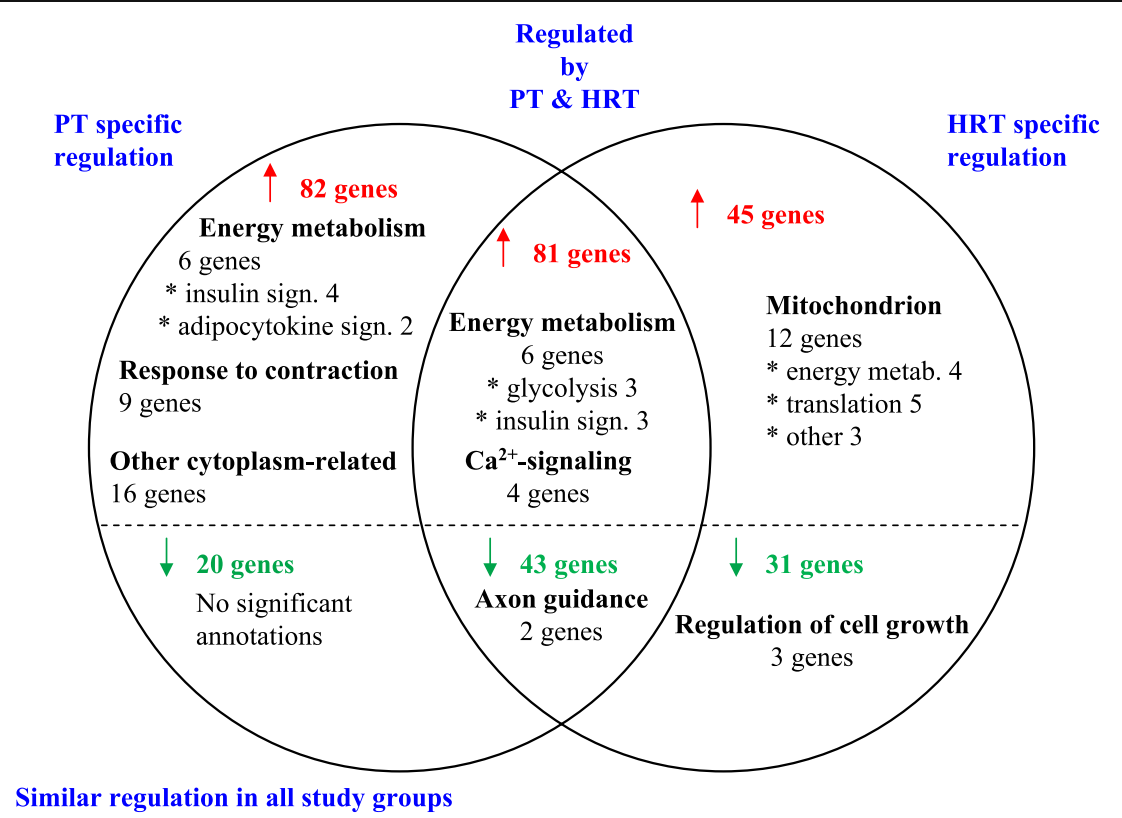

Similar regulation in all study groups

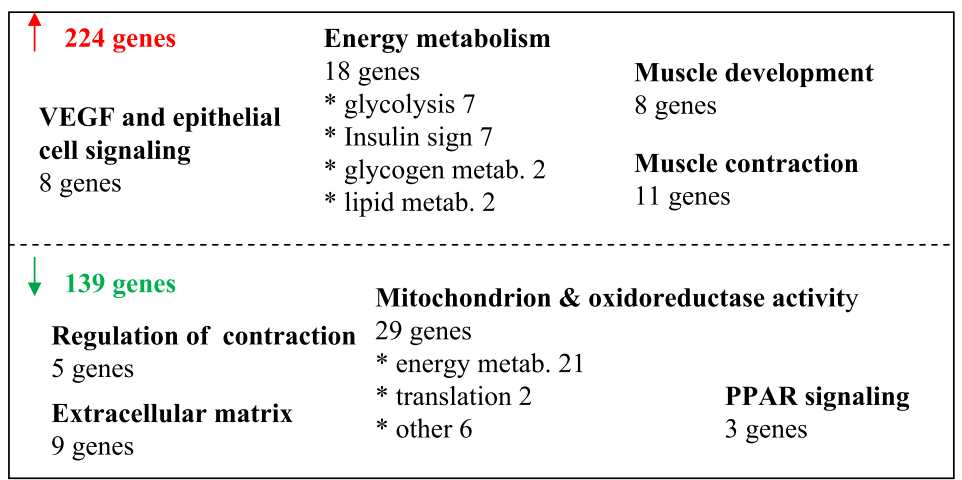

The only statistically significant downregulated pathway among both PT and HRT women was "axon guidance" (Table 3), including two moderators of Gprotein signaling, the $R G S 3$ and $S R G A P 2$. Only three of the 43 genes belonging to CL \#6 had KEGG annotation and 19 out of 43 had GO annotation, leaving 24 genes of CL \#6 without any annotations at all.

Functional categories, which were changed into same direction in all study groups

The largest and most heterogeneous clusters were CL \#1 with 224 genes and CL \#3 with 139 genes (Fig. 1a, c, Table 1). Transcription of genes in these clusters was either upregulated or downregulated within all three study groups, i.e., neither PT nor
HRT was able to reverse the regulation of these genes. CL \#1 with uniform upregulation is mainly formed of GO terms (Table 2) related to muscle development (including GO terms GO:0007517 and GO:0007519), muscle contraction (including GO:0006936, GO:0006941, and GO:0030731), and muscle energy metabolism (including GO:0005977, GO:0004368, and GO:0016600) and KEGG pathways (Table 3 ) related to energy (carbohydrate) metabolism (including pathways 04910, 00010, and 00030) as well as VEGF and epithelial cell signaling. It is notable that enrichment related to muscle carbohydrate utilization and especially glycolysis is present in several clusters. The PT specifically upregulated five "insulin signaling" genes, both PT and HRT upregulated six "glycolysis" or "insulin signaling" genes, and finally 16 genes that showed 
uniform upregulation within all study groups had "glycolysis", "glycogen metabolism" or "insulin signaling" annotation.

Other significantly and uniformly upregulated genes, which also might have direct effects on muscle functionality, were classified as "muscle development" (eight genes) or "muscle contraction" (12 genes). Among these were two genes encoding myosin heavy chain polypeptides (MYH1 and MYH8). To avoid confusion, the MYH1 gene, which encodes for fast myosin heavy chain IIx polypeptide, will be referred to as MYH IIx in this report. Transcription of MYH IIx was substantially upregulated in all study groups (FC: $2.40,1.85$ and 1.74 in the PT, HRT, and CO, respectively). The relative proportion of MyHC IIx protein was also increased in all study groups according to gel electrophoresis analysis (FC: 1.9, 1.8 and 2.2 in the PT, HRT, and CO, respectively; data not shown). Transcription of $M Y H 8$, which encodes perinatal myosin heavy chain polypeptide, was hardly detectable as upregulated in the HRT group but substantially more so in the PT and CO groups (FC: 1.84, 1.02, and 1.79 in the PT, HRT, and CO, respectively). The rest of the genes in "muscle development"-related terms were myostatin, FHL3, MAPK12, MYOD1, MEF2D, $M Y F 6$, STK23, and MYLPF. These genes were upregulated in the PT group by $25-54 \%$ and to a lesser extent in the HRT and CO groups (3-21\%), except MYOD1, which had 30\% upregulation in the CO group, 14\% upregulation in the HRT group, and only $4 \%$ in the PT group (Supporting Table S1).

Of the genes downregulated in all groups (CL \#3), the largest common terms were related to mitochondrial energy metabolism with 18 genes contributing to the significance of three functional categories (terms GO:0005739, 00190, and 00072 in Tables 2 and 3) and oxidation-reduction reactions with 14 genes belonging to one or more of the following categories: GO:0047115, GO:0016491, GO:0004033, GO:0047026, GO:0047042, GO:0032052, GO:0015721, and 00980 listed in Tables 2 and 3. The next largest significant functional category was "proteinaceous extracellular matrix" with nine downregulated genes. Also GO/ KEGG categories: "regulation of muscle contraction", "signaling through protein binding", "lipid metabolism," and "regulation of cell cycle" were affected.

\section{Discussion}

This study investigated global transcriptional changes following power type of training and estrogen containing hormonal replacement in skeletal muscle of postmenopausal women. We found 665 differentially expressed genes, which were assorted into eight nonredundant clusters. PT appeared to have broader effects on muscle metabolism, as seen in the number of affected genes (510), while effects of HRT were narrowed down to 54 changed genes. Moreover, the "without treatment" - condition led to the discovery of 161 genes with a significantly changed expression pattern. Using enrichment analysis, we were able to identify transcript groups, which were specific to PT, specific to HRT, shared with PT and HRT, and finally common to all studied, 50-57-year-old postmenopausal women (Fig. 3).

Specific transcription responding to muscle contraction

PT specifically affected transcription of nine genes known to respond to muscle contraction. Among these was STARS, which is considered to be an important mediator linking changes in actin dynamics and sarcomere structure with muscle gene expression (Kuwahara et al. 2005). Recently, Lamon et al. (2009) showed that resistance training stimulates the expression of STARS, which was associated with skeletal muscle hypertrophy. Here we show, that also plyometric power training, which improves muscle power and composition (Sipilä et al. 2001; Taaffe et al. 2005) stimulates the expression of STARS. Our finding indicates that STARS expression is induced by contraction per se and that the signaling through STARS can be directed to different pathways either to directly promote hypertrophy (Lamon et al. 2009), or to improve muscle composition and neuromuscular function (Taaffe et al. 2005). The components of such pathways are most likely co-regulated and therefore correlate closely with expression of STARS. In our data, the change in the mRNA expression of STARS did not correlate with change in any of the downstream genes investigated by Lamon et al. However, we find high correlation with other genes. Therefore, the ten most promising novel candidate genes $(r=$ $0.54-0.68, p<0.00001)$ for STARS-related regulation of muscle composition and function could be STIM, 
MRPL30, PPM1A, AFAP1L1, SYNE2, LONRF1, ETFA, $A G L$, and FHOD1.

PT and HRT have overlapping effects

on the carbohydrate metabolism-related transcription

Some mediators of the insulin signaling pathway were upregulated solely by PT (five genes) and some by both PT and HRT (six genes), suggesting overlapping effects of these two interventions. PT specifically upregulated the mRNA expression of $A K T 2$ and several other kinases as well as the expression of GLUT4. AKT protein kinases have three isoforms from which AKT2 is most important in modulating glucose homeostasis by regulating GLUT4 translocation into the plasma membrane in skeletal muscle (Gonzalez and McGraw 2009). Our result may indicate that the import of glucose into muscle cells is increased in the PT women assuming that the enhanced mRNA expression will actually lead to a larger amount of GLUT4 proteins. Ten additional genes related to the insulin signaling pathway were upregulated among all study participants. These include $O G T$, which has been recently identified as a suppressor of insulin signaling and its hepatic overexpression causes insulin resistance and dyslipidemia (Yang et al. 2008). The upregulation of the $O G T$ gene was most prominent within the $\mathrm{CO}$ women $(22 \%)$, and less obvious among the PT (12\%) and HRT (6\%) women (Supporting Table S1). OGT catalyzes the attachment of $O$-GlcNAc to proteins providing post-translational modification comparable and often competitive to phosphorylation. The rate of $O$-GlcNAcetylation is highly dependent on the availability of intracellular glucose, from which $2-5 \%$ is converted into UDP-GlcNAc, the donor substrate for GlcNAcetylation (Marshall et al. 1991). Therefore, OGT functions as an energy sensor, capable of regulating signal transduction, transcription, and proteosomal degradation (Wells et al. 2003; Copeland et al. 2008). In addition, many genes directly related to glycolysis were upregulated either in both PT and HRT groups (three genes) or in all three study groups (seven genes). The mRNA expressions of all major enzymes (PGM1, PFKM, FBP2, ALDOA, and TPII) needed for conversions of glucose to $\mathrm{C}_{3}$-carbohydrates were upregulated at the mRNA level. Also the mRNA expression of $P K M 2$, which is a glycolytic enzyme that catalyzes the transfer of a phosphoryl group from phosphoenolpyruvate to ADP thus generating ATP
(Ikeda and Noguchi 1998), was upregulated in the PT and HRT groups. Taken together, it seems that the tendency to increase transcription related to carbohydrate metabolism after menopause is further enhanced by PT and HRT and finally manifests as better muscle performance. It is also possible that after menopause, the excess of sugar metabolites starts to accumulate, which produces a need to enhance both insulin signaling and glycolysis. Further studies are needed to verify if this strain observed here at mRNA level is due to an increment in energy need per se, due to truncation in energy production or due to inefficiency in energy utilization after menopause and whether the increments at mRNA level will lead to actual increments of corresponding proteins/enzymes.

Parallel activation of calcium signaling pathway by PT and HRT

Yet another candidate pathway for improving muscle performance is the calcium signaling pathway. Myoplasmic calcium $\left(\mathrm{Ca}^{2+}\right)$ is a well-known secondary messenger involved in excitation-contraction coupling (Melzer et al. 1995) and is believed to be involved in an array of cellular functions including carbohydrate metabolism, gene transcription, protein synthesis, and mitochondrial biogenesis, further increasing the diversity of the pathway (Hook and Means 2001; Wu et al. 2002; Wright 2007; Rose and Richter 2008; Illario et al. 2009; Rose et al. 2009). In our study, five members of the calcium signaling pathway, namely two calmodulins: CALM1 and CALM3, and three calmodulin and/or $\mathrm{Ca}^{2+}$-activated kinases: PHKG1, CaMK2A, and $C a M K 2 B$, showed consistent transcriptional activation. Training increased expression of these genes by 20 $30 \%$, and the use of HRT by $0-15 \%$, while the same genes were slightly downregulated in the $\mathrm{CO}$ group (2-13\%, Supporting Table S1). It is well established that, contraction-induced elevation in $\mathrm{Ca}^{2+}$ concentration leads to rapid activation of CALMs, which in turn activate multifunctional CaMK kinases among other downstream targets (Walsh 1983). Our results suggest that the transcription of CaMK2, the most abundant CaMK in skeletal muscle, is regulated by physical exercise and that long-term PT leads to elevated basal mRNA levels. This is in line with protein level studies in which the activity of CaMK2 has been shown to be rapidly induced by exercise in an intensity dependent manner (Rose et al. 2005). It is 
also widely acknowledged that physical exercise increases the mRNA and protein expression of GLUT4. The mechanism for an exercise-induced increment is not entirely clear, but it has been suggested that it may go through an increase in intracellular $\mathrm{Ca}^{2+}$ content, which activates CaMK and calcineurin, which in turn activates specific transcription factors including MEF2 (Holmes and Dohm 2004). Our results support this hypothesis and suggest that PT also directly affects the transcription of $C a M K$, but not that of calcineurin, whose transcription was not induced in our study. The mechanism by which HRT is able to resist decrements in CALM1, CALM3, PHKG1, CaMK2A, and $C a M K 2 B$ transcription, which was seen among the $\mathrm{CO}$ women, is not known.

HRT aids in maintaining muscle mitochondrial function via transcriptional regulation

One important and interesting aspect of aging-related phenomena discovered in previous microarray studies is the enhanced negative transcriptional regulation of oxidative phosphorylation and other mitochondrial functions with advancing age (Welle et al. 2003; Welle et al. 2004; Zahn et al. 2006; Melov et al. 2007; Welle et al. 2008). This downregulation was also observed in our study with early postmenopausal, middle-aged women. In our data, 29 genes with GO annotation "mitochondrion" or related to "oxidoreductase activity" were downregulated in all study groups within the 1-year interval. However, downregulation of "mitochondrion" genes was only minimal among the HRT women being $0-13 \%$ for most of the genes and $16-23 \%$ for nine genes related to oxidation events (Supporting Table S1). Much more severe downregulation was observed in the PT (5-55\%) and CO (3-46\%) groups. Moreover, there was specific upregulation of another set of 12 "mitochondrion"-genes within the HRT women (Fig. 3). Even though the upregulation of these genes was modest $(0-13 \%)$ among the HRT women, the same genes were downregulated substantially more among the PT (12-53\%) and CO (2-33\%) women (Supporting Table S1). This data indicates that HRT may be beneficial for maintaining proper functionality of mitochondria, which seems to start accumulating negative transcriptional regulation already in the early postmenopausal years. Furthermore, contrary to strength-based resistance (Melov et al. 2007) and endurance training (Mahoney et al. 2005), the plyometric power training used in the current study was not effective in resisting negative transcriptional regulation of mitochondria. We also had some muscle samples $(n=46)$ taken 6 months after the initiation of the Ex/HRT intervention, from which we determined the amount of mitochondrial DNA relative to genomic DNA in order to count the number of mitochondria. However, we did not observe differences in the number of mitochondria between the samples of PT, HRT, and CO women (data not shown), which indicates that the regulation is on functionality rather than the number of mitochondria.

Transcriptional regulation of myogenesis and muscle contraction-related genes in all study groups

We found that several functional categories directly related to myogenesis, muscle structure, and function were affected during the first years postmenopause (Fig. 3). Eight "muscle development"-genes were upregulated within all study groups. For example, from the four members of MYOD1-family of myogenic regulatory factors (MYOD1, myogenin, MYF5, and MYF6), both MYOD1 and MYF6 were found to be upregulated within all study groups. These transcription factors have both specific and redundant functions during muscle development, and their activation is required for satellite cell differentiation during myogenesis and muscle regeneration (Yablonka-Reuveni and Rivera 1994; YablonkaReuveni et al. 1999). Also, the MEF2 transcription factor family includes four genes, which have sequential expression patterns during muscle development. The MEF2 gene, which we found to be activated among all study participants, was $M E F 2 D$, whose binding to the promoter of MYOD1 is required for increase and maintenance of MYOD1 expression during differentiation into myotubes (L'honore et al. 2007). Taken together, it seems that transcriptional regulation of myogenesis and muscle regeneration is activated in the early postmenopausal women.

Furthermore, functional categories "regulation of contraction," "muscle contraction," and "extracellular matrix" were enriched among all study groups (including 11 upregulated and 14 downregulated genes). In addition, PT specifically affected another 
group of genes that are known to respond to contraction (nine upregulated genes). In studies by Welle and co-workers (Welle et al. 2003; Welle et al. 2004), MYH8 encoding the perinatal myosin heavy chain, was found to be upregulated with aging. Similarly, we found that MYH8 was upregulated within all study groups albeit the upregulation was barely visible within the HRT group (2\%) but much more pronounced in the PT (84\%) and CO (79\%) groups (Supporting Table S1). Expression of MYH8 dominates the early skeletal muscle development, and it is re-expressed in regenerating muscles (d'Albis et al. 1988; Weiss et al. 1999). Regeneration requires the activation of quiescent satellite cells to proliferate and differentiate into myoblasts, which eventually fuse with existing muscle fibers to repair damage or to help fibers to cope with physiological demands. Even though the expression level of perinatal MYH8 was low compared to the adult $M Y H$ genes, MYH I, MYH IIa, and MYH IIx, the observed substantial increment in the expression in the PT and CO groups may indicate increased demand for myofiber regeneration. Furthermore, this demand appeared to be absent among women using HRT possibly because they were the only group able to maintain and even increase their muscle mass.

Strengths and caveats of the current study

Most of the expression array studies investigating the effects of aging (Welle et al. 2003; Welle et al. 2004; Giresi et al. 2005; Zahn et al. 2006) are crosssectional studies and compare old (65-80 years old) to younger (19-30 years old) participants neglecting the middle-aged population. Furthermore, only one study has included women (Welle et al. 2004). Therefore, our study with early postmenopausal 5057-year-old women extends the work undertaken in previous studies. We studied the transcriptional changes using the age group, which according to earlier studies (Kallman et al. 1990; Phillips et al. 1993; Samson et al. 2000) is just beginning to accumulate deteriorations in their muscle function. This age range is optimal for detecting the first alterations in transcriptome even before they are fully translated to the phenotype. The relatively small sample size may, however, affect the results. On the other hand, the long duration of our study enables us to examine true adaptation to treatments both at the phenotype and transcriptome level.
For skeletal muscle tissue, 1 year is a rather long follow-up since muscle is highly adaptive to changes in, e.g., loading conditions. Furthermore, the RCT design with repeated measures analysis and using a single HRT preparation strengthens our study by eliminating physiological and genetic differences in responses to training or HRT and, therefore, enables the detection of true intra-individual responses.

To date, many studies have used quantitative PCR (qPCR) to confirm microarray results. For example, in 16 microarray studies using human muscle tissue as a source for RNA (Roth et al. 2002; Rome et al. 2003; Welle et al. 2003; Zambon et al. 2003; Welle et al. 2004; Wittwer et al. 2004; Mahoney et al. 2005; TeranGarcia et al. 2005; Schmutz et al. 2006; Chen et al. 2007; Melov et al. 2007; Pöllänen et al. 2007; Sjogren et al. 2007; Thalacker-Mercer et al. 2007; Welle et al. 2008; Stepto et al. 2009) and indicating the use of qPCR as validation method, 2-9 genes have been reanalyzed using either the same or different RNA pool. In ten cases, the microarray results were totally confirmed, and in six cases, there were 1-2 failures (out of nine, eight, seven, six, and five genes studied). Importantly, all failures have been on genes with the low level of expression. This also holds true for the array platform used in the current paper as demonstrated by Melov et al (2007) and Pöllänen et al (2007). Building on this literature, the quality and reproducibility of microarray experiments are nowadays well established, and additional validation with qPCR seems to be unnecessary, at least as far as the lowest expression levels are not considered. A more valuable extension would come from analyzing, e.g., protein samples, which we unfortunately were unable to do for other than the MyHC proteins, due to lack of samples.

In addition to the molecular level data, we have conducted comprehensive muscle phenotype analyses including tests for muscle power, strength, performance, composition, and mass (Sipilä et al. 2001; Taaffe et al. 2005). The results obtained showed the effectiveness of the PT and HRT on these phenotypes, which we believe is due to the observed changes in muscle transcriptome.

\section{Conclusions}

This study showed that several functional gene categories, which may directly affect the preservation 
of neuromuscular performance after menopause, are already altered within the first years of the postmenopausal period and that some of these are modulated by 12 -month power training and/or hormonal replacement. The newly observed transcriptional changes partially explain phenotypic improvements after PT or HRT (Sipilä et al. 2001; Taaffe et al. 2005) and provide novel insights for further studies. For example, contraction-induced gene regulation via STARS, transcriptional activation of ALDOA and other glycolysis enzymes, regulation of signal transduction via OGT and insulin, and maintaining functionality of mitochondria as well as regulation of adult myogenesis and myofiber regeneration are all important but not thoroughly studied mechanisms involved in the regulation of muscle power, performance and quality after menopause. Taken together, our main findings indicate that PT and/or HRT may function through improving energy metabolism and response to contraction as well as by preserving functionality of mitochondria in skeletal muscle of postmenopausal women.

Acknowledgments We thank the personnel at the Turku Centre for Biotechnology (Turku, Finland) for conducting the microarray hybridizations and personnel at the GenoSyst (Turku, Finland) for providing the gene cluster analyses. Minna Toivonen is thanked for the mitochondrion copy number analysis and Pirjo Isohanni and Anu Wartiovaara for providing control plasmids for the analysis. This work was supported by grants from the Finnish Ministry of Education, the Finnish Academy, the Jenny and Antti Wihuri Foundation, and the National Graduate School of Musculoskeletal Disorders and Biomaterials. The funders had no role in study design, data collection and analysis, decision to publish, or preparation of the manuscript.

Competing Interests The authors have declared that no competing interests exists.

Open Access This article is distributed under the terms of the Creative Commons Attribution Noncommercial License which permits any noncommercial use, distribution, and reproduction in any medium, provided the original author(s) and source are credited.

\section{References}

Ashburner M, Ball CA, Blake JA, Botstein D, Butler H, Cherry JM, Davis AP, Dolinski K, Dwight SS, Eppig JT, Harris MA, Hill DP, Issel-Tarver L, Kasarskis A, Lewis S, Matese JC, Richardson JE, Ringwald M, Rubin GM,
Sherlock G (2000) Gene ontology: tool for the unification of biology. The gene ontology consortium. Nat Genet 25:25-29

Chen YW, Gregory CM, Scarborough MT, Shi R, Walter GA, Vandenborne K (2007) Transcriptional pathways associated with skeletal muscle disuse atrophy in humans. Physiol Genomics 31:510-520

Cheng S, Sipilä S, Taaffe DR, Puolakka J, Suominen H (2002) Change in bone mass distribution induced by hormone replacement therapy and high-impact physical exercise in post-menopausal women. Bone 31:126-135

Copeland RJ, Bullen JW, Hart GW (2008) Cross-talk between GlcNAcylation and phosphorylation: roles in insulin resistance and glucose toxicity. Am J Physiol Endocrinol Metab 295:E17-E28

d'Albis A, Couteaux R, Mira JC, Janmot C, Roulet A (1988) Myosin isoforms synthesized during regeneration of fast contraction skeletal muscle regeneration, in the presence of motor nerve and after denervation. Study in adult rats and mice. Reprod Nutr Dev 28:753-756

Dobs AS, Nguyen T, Pace C, Roberts CP (2002) Differential effects of oral estrogen versus oral estrogen-androgen replacement therapy on body composition in postmenopausal women. J Clin Endocrinol Metab 87:1509-1516

Edgar R, Domrachev M, Lash AE (2002) Gene expression omnibus: NCBI gene expression and hybridization array data repository. Nucleic Acids Res 30:207-210

Gautier L, Cope L, Bolstad BM, Irizarry RA (2004) Affyanalysis of Affymetrix GeneChip data at the probe level. Bioinformatics 20:307-315

Giresi PG, Stevenson EJ, Theilhaber J, Koncarevic A, Parkington J, Fielding RA, Kandarian SC (2005) Identification of a molecular signature of sarcopenia. Physiol Genomics 21:253-263

Gonzalez E, McGraw TE (2009) Insulin-modulated AKT subcellular localization determines AKT isoform-specific signaling. Proc Natl Acad Sci USA 106:7004-7009

Goodpaster BH, Kelley DE, Thaete FL, He J, Ross R (2000) Skeletal muscle attenuation determined by computed tomography is associated with skeletal muscle lipid content. J Appl Physiol 89:104-110

Greenlund LJ, Nair KS (2003) Sarcopenia-consequences, mechanisms, and potential therapies. Mech Ageing Dev 124:287-299

Häkkinen K, Alen M, Kallinen M, Newton RU, Kraemer WJ (2000) Neuromuscular adaptation during prolonged strength training, detraining and re-strength-training in middle-aged and elderly people. Eur J Appl Physiol 83:51-62

Hazell T, Kenno K, Jakobi J (2007) Functional benefit of power training for older adults. J Aging Phys Act 15:349-359

Henwood TR, Riek S, Taaffe DR (2008) Strength versus muscle power-specific resistance training in communitydwelling older adults. J Gerontol A Biol Sci Med Sci 63:83-91

Holmes B, Dohm GL (2004) Regulation of GLUT4 gene expression during exercise. Med Sci Sports Exerc 36:1202-1206

Hook SS, Means AR (2001) Ca(2+)/CaM-dependent kinases: from activation to function. Annu Rev Pharmacol Toxicol 41:471-505 
Hoppeler H, Howald H, Conley K, Lindstedt SL, Claassen H, Vock P, Weibel ER (1985) Endurance training in humans: aerobic capacity and structure of skeletal muscle. J Appl Physiol 59:320-327

Ikeda Y, Noguchi T (1998) Allosteric regulation of pyruvate kinase M2 isozyme involves a cysteine residue in the intersubunit contact. J Biol Chem 273:12227-12233

Illario M, Monaco S, Cavallo AL, Esposito I, Formisano P, D'Andrea L, Cipolletta E, Trimarco B, Fenzi G, Rossi G, Vitale M (2009) Calcium-calmodulin-dependent kinase II (CaMKII) mediates insulin-stimulated proliferation and glucose uptake. Cell Signal 21:786-792

Kallman DA, Plato CC, Tobin JD (1990) The role of muscle loss in the age-related decline of grip strength: crosssectional and longitudinal perspectives. J Gerontol 45: M82-M88

Kanehisa M, Goto S, Hattori M, Aoki-Kinoshita KF, Itoh M, Kawashima S, Katayama T, Araki M, Hirakawa M (2006) From genomics to chemical genomics: new developments in KEGG. Nucleic Acids Res 34:D354-D357

Katula JA, Rejeski WJ, Marsh AP (2008) Enhancing quality of life in older adults: a comparison of muscular strength and power training. Health Qual Life Outcomes $6: 45$

Kenny AM, Kleppinger A, Wang Y, Prestwood KM (2005) Effects of ultra-low-dose estrogen therapy on muscle and physical function in older women. J Am Geriatr Soc 53:1973-1977

Kuwahara K, Barrientos T, Pipes GC, Li S, Olson EN (2005) Muscle-specific signaling mechanism that links actin dynamics to serum response factor. Mol Cell Biol 25:3173-3181

Lamon S, Wallace MA, Leger B, Russell AP (2009) Regulation of STARS and its downstream targets suggest a novel pathway involved in human skeletal muscle hypertrophy and atrophy. J Physiol

L'honore A, Rana V, Arsic N, Franckhauser C, Lamb NJ, Fernandez A (2007) Identification of a new hybrid serum response factor and myocyte enhancer factor 2-binding element in MyoD enhancer required for MyoD expression during myogenesis. Mol Biol Cell 18:1992-2001

Mahoney DJ, Parise G, Melov S, Safdar A, Tarnopolsky MA (2005) Analysis of global mRNA expression in human skeletal muscle during recovery from endurance exercise. FASEB J 19:1498-1500

Marshall S, Bacote V, Traxinger RR (1991) Discovery of a metabolic pathway mediating glucose-induced desensitization of the glucose transport system. Role of hexosamine biosynthesis in the induction of insulin resistance. J Biol Chem 266:4706-4712

Melov S, Tarnopolsky MA, Beckman K, Felkey K, Hubbard A (2007) Resistance exercise reverses aging in human skeletal muscle. PLoS ONE 2:e465

Melzer W, Herrmann-Frank A, Luttgau HC (1995) The role of $\mathrm{Ca} 2+$ ions in excitation-contraction coupling of skeletal muscle fibres. Biochim Biophys Acta 1241:59-116

Nelson HD (2008) Menopause. Lancet 371:760-770

Orr R, Raymond J, Fiatarone Singh M (2008) Efficacy of progressive resistance training on balance performance in older adults: a systematic review of randomized controlled trials. Sports Med 38:317-343
Orsatti FL, Nahas EA, Maesta N, Nahas-Neto J, Burini RC (2008) Plasma hormones, muscle mass and strength in resistance-trained postmenopausal women. Maturitas 59:394-404

Paterson DH, Jones GR, Rice CL (2007) Ageing and physical activity: evidence to develop exercise recommendations for older adults. Can J Public Health 98(Suppl 2):S69S108

Phillips SK, Rook KM, Siddle NC, Bruce SA, Woledge RC (1993) Muscle weakness in women occurs at an earlier age than in men, but strength is preserved by hormone replacement therapy. Clin Sci (Lond) 84:95-98

Pöllänen E, Ronkainen PH, Suominen H, Takala T, Koskinen S, Puolakka J, Sipilä S, Kovanen V (2007) Muscular transcriptome in postmenopausal women with or without hormone replacement. Rejuvenation Res 10:485-500

Porter MM (2006) Power training for older adults. Appl Physiol Nutr Metab 31:87-94

Ribom EL, Piehl-Aulin K, Ljunghall S, Ljunggren O, Naessen $T$ (2002) Six months of hormone replacement therapy does not influence muscle strength in postmenopausal women. Maturitas 42:225-231

Rome S, Clement K, Rabasa-Lhoret R, Loizon E, Poitou C, Barsh GS, Riou JP, Laville M, Vidal H (2003) Microarray profiling of human skeletal muscle reveals that insulin regulates approximately 800 genes during a hyperinsulinemic clamp. J Biol Chem 278:18063-18068

Ronkainen PH, Kovanen V, Alen M, Pöllänen E, Palonen EM, Ankarberg-Lindgren C, Hämäläinen E, Turpeinen U, Kujala UM, Puolakka J, Kaprio J, Sipilä S (2009) Postmenopausal hormone replacement therapy modifies skeletal muscle composition and function: a study with monozygotic twin pairs. J Appl Physiol

Rose AJ, Broholm C, Kiillerich K, Finn SG, Proud CG, Rider MH, Richter EA, Kiens B (2005) Exercise rapidly increases eukaryotic elongation factor 2 phosphorylation in skeletal muscle of men. J Physiol 569:223-228

Rose AJ, Richter EA (2008) Regulatory mechanisms of skeletal muscle protein turnover during exercise. J Appl Physiol

Rose AJ, Alsted TJ, Jensen TE, Kobbero JB, Maarbjerg SJ, Jensen J, Richter EA (2009) A Ca(2+)-calmodulin-eEF2KeEF2 signalling cascade, but not AMPK, contributes to the suppression of skeletal muscle protein synthesis during contractions. J Physiol 587:1547-1563

Roth SM, Ivey FM, Martel GF, Lemmer JT, Hurlbut DE, Siegel EL, Metter EJ, Fleg JL, Fozard JL, Kostek MC, Wernick DM, Hurley BF (2001) Muscle size responses to strength training in young and older men and women. J Am Geriatr Soc 49:1428-1433

Roth SM, Ferrell RE, Peters DG, Metter EJ, Hurley BF, Rogers MA (2002) Influence of age, sex, and strength training on human muscle gene expression determined by microarray. Physiol Genomics 10:181-190

Samson MM, Meeuwsen IB, Crowe A, Dessens JA, Duursma SA, Verhaar HJ (2000) Relationships between physical performance measures, age, height and body weight in healthy adults. Age Ageing 29:235-242

Schmutz S, Dapp C, Wittwer M, Vogt M, Hoppeler H, Fluck M (2006) Endurance training modulates the muscular transcriptome response to acute exercise. Pflugers Arch 451:678-687 
Sipilä S, Taaffe DR, Cheng S, Puolakka J, Toivanen J, Suominen H (2001) Effects of hormone replacement therapy and high-impact physical exercise on skeletal muscle in post-menopausal women: a randomized placebo-controlled study. Clin Sci (Lond) 101:147-157

Sjogren K, Leung KC, Kaplan W, Gardiner-Garden M, Gibney J, Ho KK (2007) Growth hormone regulation of metabolic gene expression in muscle: a microarray study in hypopituitary men. Am J Physiol Endocrinol Metab 293:E364-E371

Skelton DA, Phillips SK, Bruce SA, Naylor CH, Woledge RC (1999) Hormone replacement therapy increases isometric muscle strength of adductor pollicis in post-menopausal women. Clin Sci (Lond) 96:357-364

Smyth GK (2004) Linear models and empirical bayes methods for assessing differential expression in microarray experiments. Stat Appl Genet Mol Biol 3:Article3

Stepto NK, Coffey VG, Carey AL, Ponnampalam AP, Canny BJ, Powell D, Hawley JA (2009) Global gene expression in skeletal muscle from well-trained strength and endurance athletes. Med Sci Sports Exerc 41:546-565

Taaffe DR (2006) Sarcopenia-exercise as a treatment strategy. Aust Fam Physician 35:130-134

Taaffe DR, Sipilä S, Cheng S, Puolakka J, Toivanen J, Suominen H (2005) The effect of hormone replacement therapy and/or exercise on skeletal muscle attenuation in postmenopausal women: a yearlong intervention. Clin Physiol Funct Imaging 25:297-304

Tanko LB, Movsesyan L, Svendsen OL, Christiansen C (2002) The effect of hormone replacement therapy on appendicular lean tissue mass in early postmenopausal women. Menopause 9:117-121

Teran-Garcia M, Rankinen T, Koza RA, Rao DC, Bouchard C (2005) Endurance training-induced changes in insulin sensitivity and gene expression. Am J Physiol Endocrinol Metab 288:E1168-E1178

Thalacker-Mercer AE, Fleet JC, Craig BA, Carnell NS, Campbell WW (2007) Inadequate protein intake affects skeletal muscle transcript profiles in older humans. Am J Clin Nutr 85:1344 1352

Timmons JA, Larsson O, Jansson E, Fischer H, Gustafsson T, Greenhaff PL, Ridden J, Rachman J, Peyrard-Janvid M, Wahlestedt C, Sundberg CJ (2005) Human muscle gene expression responses to endurance training provide a novel perspective on Duchenne muscular dystrophy. FASEB J 19:750-760

Walsh MP (1983) Calmodulin and its roles in skeletal muscle function. Can Anaesth Soc J 30:390-398

Weiss A, Schiaffino S, Leinwand LA (1999) Comparative sequence analysis of the complete human sarcomeric myosin heavy chain family: implications for functional diversity. J Mol Biol 290:61-75

Welle S, Brooks AI, Delehanty JM, Needler N, Thornton CA (2003) Gene expression profile of aging in human muscle. Physiol Genomics 14:149-159

Welle S, Brooks AI, Delehanty JM, Needler N, Bhatt K, Shah B, Thornton CA (2004) Skeletal muscle gene expression profiles in 20-29 year old and 65-71 year old women. Exp Gerontol 39:369-377

Welle S, Tawil R, Thornton CA (2008) Sex-related differences in gene expression in human skeletal muscle. PLoS ONE 3:e1385

Wells L, Whelan SA, Hart GW (2003) O-GlcNAc: a regulatory post-translational modification. Biochem Biophys Res Commun 302:435-441

Wittwer M, Billeter R, Hoppeler H, Fluck M (2004) Regulatory gene expression in skeletal muscle of highly endurancetrained humans. Acta Physiol Scand 180:217-227

48th WMA General Assembly (1996) Nurenberg doctors' trial: declaration of Helsinki (1964). BMJ 313:1448-1449

Wright DC (2007) Mechanisms of calcium-induced mitochondrial biogenesis and GLUT4 synthesis. Appl Physiol Nutr Metab 32:840-845

Wu H, Kanatous SB, Thurmond FA, Gallardo T, Isotani E, Bassel-Duby R, Williams RS (2002) Regulation of mitochondrial biogenesis in skeletal muscle by CaMK. Science 296:349-352

Yablonka-Reuveni Z, Rivera AJ (1994) Temporal expression of regulatory and structural muscle proteins during myogenesis of satellite cells on isolated adult rat fibers. Dev Biol 164:588-603

Yablonka-Reuveni Z, Rudnicki MA, Rivera AJ, Primig M, Anderson JE, Natanson P (1999) The transition from proliferation to differentiation is delayed in satellite cells from mice lacking MyoD. Dev Biol 210:440-455

Yang X, Ongusaha PP, Miles PD, Havstad JC, Zhang F, So WV, Kudlow JE, Michell RH, Olefsky JM, Field SJ, Evans RM (2008) Phosphoinositide signalling links OGlcNAc transferase to insulin resistance. Nature 451:964-969

Zahn JM, Sonu R, Vogel H, Crane E, Mazan-Mamczarz K, Rabkin R, Davis RW, Becker KG, Owen AB, Kim SK (2006) Transcriptional profiling of aging in human muscle reveals a common aging signature. PLoS Genet 2:e115

Zambon AC, McDearmon EL, Salomonis N, Vranizan KM, Johansen KL, Adey D, Takahashi JS, Schambelan M, Conklin BR (2003) Time-and exercise-dependent gene regulation in human skeletal muscle. Genome Biol 4: R61 